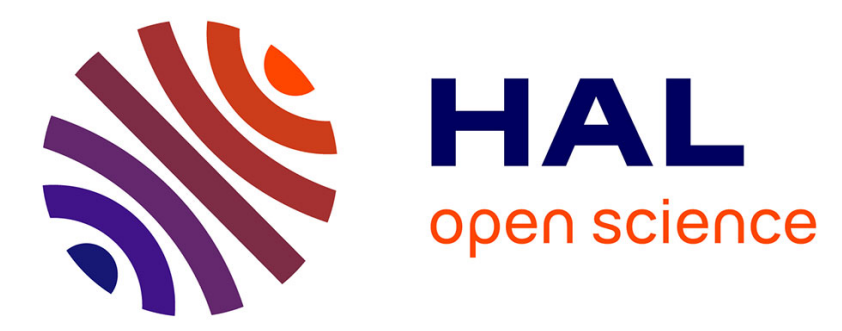

\title{
Heterogeneous lyophobic systems based on pure silica ITH-type zeolites: high pressure intrusion of water and electrolyte solutions
}

\author{
L. Ronchi, H. Nouali, T. Daou, J. Patarin, A. Ryzhikov
}

\section{- To cite this version:}

L. Ronchi, H. Nouali, T. Daou, J. Patarin, A. Ryzhikov. Heterogeneous lyophobic systems based on pure silica ITH-type zeolites: high pressure intrusion of water and electrolyte solutions. New Journal of Chemistry, 2017, 41 (24), pp.15087-15093. 10.1039/C7NJ03470A . hal-03543883

\section{HAL Id: hal-03543883 \\ https://hal.science/hal-03543883}

Submitted on 26 Jan 2022

HAL is a multi-disciplinary open access archive for the deposit and dissemination of scientific research documents, whether they are published or not. The documents may come from teaching and research institutions in France or abroad, or from public or private research centers.
L'archive ouverte pluridisciplinaire HAL, est destinée au dépôt et à la diffusion de documents scientifiques de niveau recherche, publiés ou non, émanant des établissements d'enseignement et de recherche français ou étrangers, des laboratoires publics ou privés. 


\title{
Heterogeneous lyophobic systems based on pure silica ITH-type zeolite: high pressure intrusion of water and electrolyte solutions
}

\author{
L. Ronchi, H. Nouali, T. J. Daou*, J. Patarin and A. Ryzhikov** \\ "Université de Strasbourg (UdS), Université de Haute Alsace (UHA), Axe Matériaux \\ a Porosité Controbiée (MPC), Institut de Science des Motérioux de Mulhouse (ISZM) \\ UMR 7361, ENSCMu, 3 bis rue Alfred Wemer, F-68093 Mulhouse, France. \\ - Email: iean doounuha.ft Telephane number: +33389336739 , Fax number. \\ $+33389336885$ \\ $*$ Email: andrey.ryzhikovieuha.ft, Teiephone number: +33389336754 , Fax \\ number: +33389336885
}

The energetic performances of pure silica ITH-type zeolite were studied by high pressure intrusion-extrusion in water and $\mathrm{LiCl}$ aqueous solutions at different concentrations. When pure water is intruded, a bumper behavior is exhibited with an intrusion pressure of $82 \mathrm{MPa}$ and an absorbed energy of $6.6 \mathrm{~J} \mathrm{~g}$. Changing the intruded liquid from water to LiCl aqueous solutions, an increase of the intrusion pressure is observed with 119,175 and $280 \mathrm{MPa}$ for $5 \mathrm{M}, 10 \mathrm{M}$ and $20 \mathrm{M} \mathrm{LiCl}$ aqueous solutions, respectively. The energy that the latter system can absorb $\left(30.8 \mathrm{~J} \mathrm{~g}^{-1}\right)$ is among the highest ever reported. A change of the behavior with LiCl concentration is also observed. The "ITH-type zeosil-20 M LiCl solution" system demonstrates a combination of bumper and shock-absorber behavior, whereas a bumper behavior is displayed for water and the other $\mathrm{LiCl}$ aqueous solutions. All the zeolite samples were characterized before and after intrusion-extrusion experiments (XRD, SEM, $\mathrm{N}_{2}$ adsorption-desorption, TG and NMR analysis) in order to understand the influence of LiCl concentration on "zeosil-liquid" bystem behavior.

\section{Introduction}

Zeolites are microporous crystalline solids with a framework composed by $\mathrm{TO}_{4}(\mathrm{~T}=\mathrm{Al}, \mathrm{Si})$ tetrahedra units that form a porous structure with channels and cages. They are widely used in molecular sieving, adsorption, industrial catalysis and ion-exchange processes. ${ }^{1}$ Since 2001 a new application field was developed by our group $p^{2,3}$ for pure silica zeolites (zeosils) which demonstrate hydrophobic properties: the storage or the absorption of mechanical energy by high pressure water intrusion. ${ }^{4-12}$ During the intrusion process the liquid water is transformed into a multitude of molecular clusters inside the pores of the material that corresponds to the conversion of the supplied mechanical energy into the one of solid-liquid interface. ${ }^{13,14}$ When the pressure is released, three different behaviors can be observed depending on the structural features of the zeosil: a spring, a shock-absorber or a bumper one, when the supplied mechanical energy is restored, dissipated or absorbed, respectively. Such systems based on porous solids and non-wetting liquids, also called heterogeneous lyophobic systems, can be used for applications in absorption, storage and generation of mechanical energy, in particular, in the fields of automobile and aerospace industry and industrial security. ${ }^{15-21}$ Other porous materials, such as hydrophobized porous silicas ${ }^{22-24}$ and Metal-Organic Frameworks (MOFs) ${ }^{25-28}$ can be also used for these systems.

During these years, a great effort was made to understand the relationship between the physicochemical and topological parameters of the zeolite framework (hydrophobic/hydrophilic character, pore size, geometry and channel dimensionality) and the behavior and the energetic performances of "zeosilwater" systems. ${ }^{9,29}$ The most part of the studied "zeosil-water" systems show a spring behavior, but some of them display a shock- absorber (RRO ${ }^{6}$, bumper (*BEA ${ }^{2}$, IFR $^{5}, \mathrm{LTA}^{30}$ ) or mixed $\left(\mathrm{STF}^{12}, \mathrm{CHA}^{31}\right)$ behavior. It was observed that cage-type zeosils demonstrated generally lower values of water intrusion pressure in comparison with channel-type ones. It was also found that for zeosils with channel-type pore system, the intrusion pressure was determined by the pore opening (small pores lead to high intrusion pressure), while for zeosils with cage-type pore system, the cage diameter is a key parameter. Nevertheless the study of new "zeosils-water" systems presents a high interest, since it allows us to better understand the relationship between the structure of the zeosil and its energetic performances, in particularly by comparison between zeosils with similar structure.

This article, is devoted to the study of energetic performances of pure silica ITH-type zeolite (hereafter Si-ITH), which has been never tested before for this application. This zeosil, synthesized for the first time by Boix et al. ${ }^{32}$, is characterized by a $3 D$ intercrossed channel pore system with the peculiarity of a 9 membered-ring (MR) pore opening $\left(4.0 \times 4.9 \AA^{2}\right)^{33}$ for the channel that runs parallel to the crystallographic $a$ axis. The channels parallel to the $b$ and $c$ axes have $10 \mathrm{MR}$ pore 
apertures of $4.7 \times 5.1 \AA^{2}$ and $4.8 \times 5.7 \AA^{2}$, respectively. Another particularity of the pore system of this zeolite is the presence of a sinuosity along the channels parallel to the $\mathrm{c}$ axis. ${ }^{32}$

The energetic performances of ITH-type zeosil can be compared with the ones of other already tested channel-type pure silica zeolites: MFI- (Silicalite-1) ${ }^{2}$ and MEL-type ${ }^{9}$ zeosils characterized by a 3D channel pore system with $10 \mathrm{MR}$ pore openings and FER-type zeosils ${ }^{34}$, which has a $2 \mathrm{D}$ channel pore system with $8 \mathrm{MR}$ and $10 \mathrm{MR}$ smaller pore apertures.

In recent years it was found that a use of electrolyte aqueous solutions allowed to improve the energetic performances of "hydrophobic zeolite-liquid" systems by a considerable increase of intrusion pressure. ${ }^{30,35,36-42}$ The pressure can be increased by up to 7.4 times in comparison with pure water, as it was observed for the intrusion of $20 \mathrm{M} \mathrm{LiCl}$ aqueous solution in pure silica LTA-type zeolite. ${ }^{30} \mathrm{~A}$ use of highly concentrated aqueous solutions can even change the behavior of the "zeolite-liquid" system, as it was observed for "BEA- ${ }^{38}$, LTA ${ }^{30}$ and OKO-type ${ }^{39}$ zeosils.

Our study focuses on the intrusion-extrusion of water and LiCl aqueous solutions in ITH-type zeosil with a complete characterization of zeosil samples before and after the high pressure experiments. The main text of the article should appear here with headings as appropriate.

\section{Results and discussion}

Intrusion-extrusion isotherms. The pressure-volume diagrams (intrusion-extrusion isotherms) of the "Si-ITH-water" and "SiITH-LiCl aqueous solutions" systems are shown in Figure 1 and the corresponding data are reported in Table 2 . For all the systems, three intrusion-extrusion cycles were carried out. For clarity only the first two cycles are presented, since the second (II) and third (III) cycle are superimposable. The low pressure range (0-5 $\mathrm{MPa}$ ) is not shown, since the observed volume variation is related with the filling of the interparticular porosity of the zeosil pellet. ${ }^{11}$

A completely irreversible intrusion of water is observed (no extrusion) for "Si-ITH-water" system, that corresponds to a bumper behavior. Such behavior is completely different from the one observed for the zeosils with similar structure (MFI, MEL), which demonstrate a fully reversible spring one. ${ }^{9}$ Normally, the bumper behavior is caused by the interaction of the intruded water molecules with the dangling $-\mathrm{OH}$ groups already present in the zeosils ${ }^{4}$ or formed (due to the breaking of siloxane bridges) during the intrusion-extrusion experiments. $^{38}$

At the moment the bumper behavior was observed only for ${ }^{*} \mathrm{BEA}^{38}$, IFR ${ }^{5}$ and $\mathrm{LTA}^{30}{ }^{30}$ type zeosils (3D channel pore system with 12 MR openings, 1D channel pore system with side pockets and $12 \mathrm{MR}$ openings and 3D cage pore system with 8 MR openings, respectively). A partially irreversible intrusion was also demonstrated for $\mathrm{CHA}^{31}$ and STF-type ${ }^{12}$ zeosils (3D cage pore system with $8 \mathrm{MR}$ openings and 1D channel pore system with side pockets and $10 \mathrm{MR}$ openings). Since all above mentioned zeosils have different framework structure and pore system, it can be concluded that the behavior does not depend on the type and the dimensionality of the pore system, but is

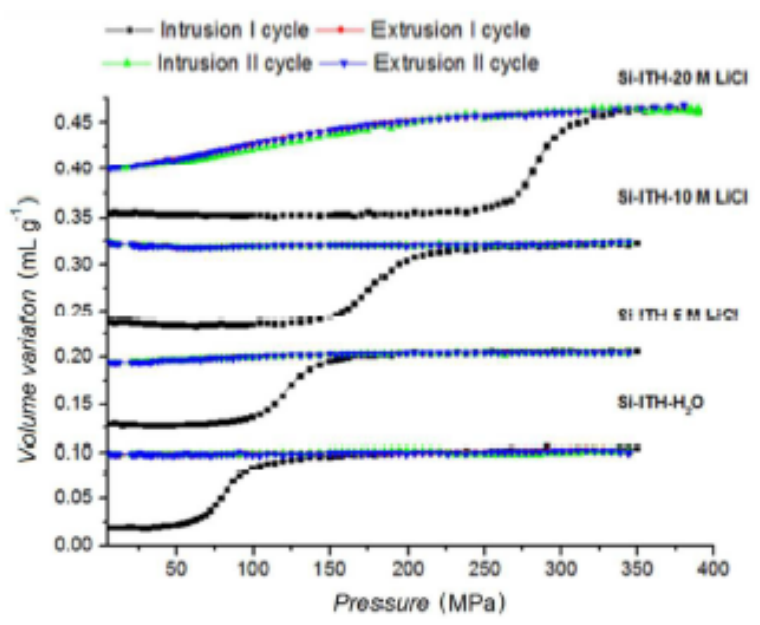

Figure 1. The first and the second intrusion-extrusion cycles of the "Si-ITH-water" and "Si-ITH- LiCl aqueous solution" systems. For clarity, the intrusion-extrusion isotherms are shifted along the $\mathrm{Y}$ axis.

Table 1. Characteristics of the Si-ITH samples: Intrusion ( $P_{\text {int }}$ ) and Extrusion ( $\left.P_{\text {ext }}\right)$ Pressures, Intruded $\left(V_{\text {int }}\right)$ and Extruded $\left(V_{\text {ext }}\right)$ Volumes, Stored $\left(E_{s}\right)$ and Restored $\left(E_{r}\right)$ Energies after water and $\mathrm{LiCl}$ aqueous solution intrusion-extrusion experiments at different salt concentrations (5, 10 and $20 \mathrm{M})$.

\begin{tabular}{|c|c|c|c|c|c|c|c|}
\hline System & $\begin{array}{l}\text { Pert } \\
\text { [MPa] }\end{array}$ & $\begin{array}{l}\mathrm{P}_{e x{ }^{3}} \\
\text { [MPa] }\end{array}$ & $\begin{array}{l}V_{i m t}{ }^{2} \\
{\left[m L^{-4}\right]}\end{array}$ & $\begin{array}{l}V_{a t}{ }^{3} \\
\left\{m L_{B}^{-4} \mid\right.\end{array}$ & $\begin{array}{l}\mathrm{E}_{4}{ }^{b} \\
\| \mathrm{g} \mathrm{g}^{-\mathrm{L}} \mid\end{array}$ & $\begin{array}{l}E_{r}{ }^{c} \\
\text { [f } \\
\left.{ }_{1}\right]\end{array}$ & $\begin{array}{l}\text { Yield } \\
(\%)^{d}\end{array}$ \\
\hline $\mathrm{Si}-\mathrm{ITH}-\mathrm{H}_{2} \mathrm{O}$ & 82 & . & 0.08 & . & 6.6 & . & . \\
\hline Si-ITH-SM LiCI & 119 & . & 0.08 & . & 9.5 & . & . \\
\hline Si-TTH-10M Lid & 175 & . & 0.08 & . & 14.0 & . & . \\
\hline \multirow{2}{*}{ Si-TTH-20M Lid } & $280 \% /$ & $117 \% /$ & $0.11 \%$ & $0.06 \%$ & $30.8 \%$ & $6.7 \%$ & $22 \%$ \\
\hline & $135 \%$ & ${ }_{117} * *$ & $0.06 *$ & $0.06 * *$ & $8.3 *$ & $6.7 *$ & $81 *$ \\
\hline
\end{tabular}

"Determined from intrusion-extrusion isotherms. "Stored energy $E_{a}=V_{i=t} \times$ $P_{\text {int }}{ }^{\mathrm{c}}$ Restored energy $E_{\mathrm{r}}=\mathrm{V}_{\text {eat }} \times \mathrm{P}_{\text {ext. }}{ }^{\mathrm{d}}$ \% energy yield $=E_{\mathrm{r}} / \mathrm{E}_{2} \times 100$. * first cycle. "* second and third cycle.

possibly related with the stability of the zeosil framework (breaking of siloxane bonds).

The intrusion pressure for the "Si-ITH - water" system is lower than the one observed for MFI-type zeosil, but higher than that of MEL-type zeosil: $82 \mathrm{MPa}$ against 96 and $63 \mathrm{MPa}$, respectively. However, it should be noticed that the MEL-type sample contained higher content of defects before intrusionextrusion experiments ${ }^{9}$, which can explain its lower intrusion pressure. Thus, even the zeosils with very close pore system can show significantly different intrusion pressure values. Other zeosils with channel pore system and $10 \mathrm{MR}$ pore openings demonstrate even more elevated intrusion pressure value: $147 \mathrm{MPa}$ for FER-type zeosil (2D channel system with 10 
and $8 \mathrm{MR}$ openings $)^{34}, 186$ and $176 \mathrm{MPa}$ for TON- and MTTtype ones (1D channel system), respectively. ${ }^{7,12}$ The intruded volume for ITH-type zeosil is $0.08 \mathrm{~mL} \mathrm{~g}^{-1}$, that is a little lower in comparison with MFI-type zeosil $\left(0.10 \mathrm{~mL} \mathrm{~g}^{-1}\right)$, but the latter has slightly higher pore volume according to $\mathrm{N}_{2}$ adsorption desorption measurements $\left(0.18\right.$ instead of $0.16 \mathrm{~mL} \mathrm{~g}^{-1}$, see below).

A bumper behavior with a completely irreversible intrusion is observed not only for water, but also for $\mathrm{LiCl}$ aqueous solutions with the concentration up to $10 \mathrm{M}$, whereas the "SiITH-20 M LiCl aqueous solution" system demonstrates a partially reversible intrusion. In the first cycle, after intrusion $\left(P_{\text {int }}=280 \mathrm{MPa}, V_{\text {int }}=0.11 \mathrm{~mL} \mathrm{~g}^{-1}\right)$ of $20 \mathrm{M} \mathrm{LiCl}$ aqueous solution, when the pressure is released, a part of liquid $\left(V_{\text {ext }}=\right.$ $0.06 \mathrm{~mL} \mathrm{~g}^{-1}$ ) is extruded at $P_{\text {ext }}=117 \mathrm{MPa}$. In the second and third cycles, the same amount of the solution is intruded at $\mathrm{P}_{\mathrm{int}}$ $=138 \mathrm{MPa}$, that is considerably lower than the one of the first cycle, and entirely extruded. Thus, the system demonstrates a combination of bumper and shock-absorber behavior in the first cycle and pure shock-absorber behavior in following ones. Therefore, for the maximal $\mathrm{LiCl}$ concentration a change of the system response occurs. In our previous works ${ }^{30,38,39}$ the change of the system behavior was ascribed to the difference in the nature of the intruded liquid. The intrusion of highly concentrated solutions led to a lower defect formation in the zeosil framework since only solvated ions $\left(\mathrm{Li}^{(} \mathrm{H}_{2} \mathrm{O}\right)^{+} \times$and $\left.\mathrm{Cl}\left(\mathrm{H}_{2} \mathrm{O}\right)_{y}\right)$ are intruded with no free or weakly bounded water molecules which can break siloxane bridges. ${ }^{38}$ Such effect was also observed in the case of LTA- ${ }^{30}$ and "BEA-type ${ }^{38}$ zeosils. However, in the case of ITH-type zeosil the formation of defects is less pronounced (see below), thus, an additional explanation could be a lower interaction of solvated ions with silanol groups in comparison with free water molecules. In both cases the system behavior becomes more reversible with the most concentrated LiCl solutions and a considerably lower defect formation was observed in comparison with water intrusion. However, for every change of system behavior some particularities are observed. In the case of LTA-type zeosil, as for $\mathrm{Si}-\mathrm{ITH}$, the system shifts from a bumper to a combination of bumper and shock- absorber behavior, but the change is demonstrated already from $10 \mathrm{M} \mathrm{LiCl}$ aqueous solution. ${ }^{30}$ While, the "BEA-type zeosil shows a completely reversible shock-absorber behavior when intruded with $15 \mathrm{M}$ and $20 \mathrm{M}$ $\mathrm{LiCl}$ aqueous solution and a bumper behavior for water and 10 $\mathrm{M} \mathrm{LiCl}$ aqueous solution. ${ }^{38}$

A strong rise of the intrusion pressure is observed with the increase of the electrolyte concentration. The dependence of the intrusion pressure on $\mathrm{LiCl}$ concentration is linear, as it can be seen in Figure 2. The pressure increases from $82 \mathrm{MPa}$ for water to 119,175 and $280 \mathrm{MPa}$ for $5 \mathrm{M}, 10 \mathrm{M}$ and $20 \mathrm{M} \mathrm{LiCl}$ aqueous solution, respectively. Thus, an augmentation of 3.4 times in comparison with water is obtained, that is slightly higher than in the case of MFI-type zeosil, where an increase of 2.9 times was observed. ${ }^{35}$ This higher increase can be related with the smaller size of pore openings in ITH structure. According to the literature, the rise of intrusion pressure can be explained by a higher surface tension of electrolyte aqueous solution in comparison with water $r^{43,44}$, by osmotic phenomena ${ }^{45,46}$, by confinement effect of nanopore walls ${ }^{41}$ or by ion desolvation. ${ }^{36,47}$ Recent studies ${ }^{48}$ demonstrate that during intrusion-extrusion experiments in pure silica FER-type zeolite using $\mathrm{MgCl}_{2}{ }^{-21} \mathrm{H}_{2} \mathrm{O}$ aqueous solution, the ions are intruded into the zeosil porosity. Surprisingly, it was found that

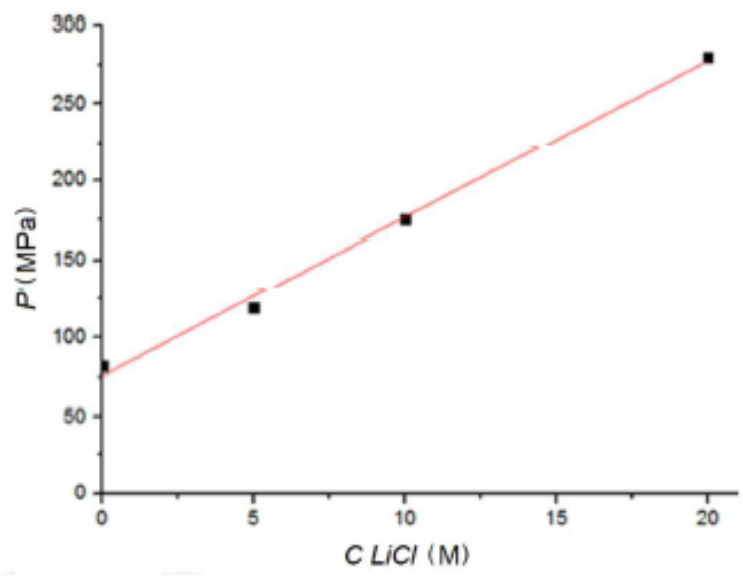

Figure 2. Dependence of the intrusion pressure on $\mathrm{LiCl}$ concentration in aqueous solutions.

the solution intruded into the pores $\left(\mathrm{MgCl}_{2} \cdot 10 \mathrm{H}_{2} \mathrm{O}\right)$ is more concentrated than the initial one. The decrease of the water content and, thus, the higher concentration of the intruded solution could be reasonably the result of the hydrophobic nature of the host zeolite matrix. Therefore, the partial ion desolvation hypothesis seems to be confirmed. The concentrated solution has better wetting properties to the pore walls than pure water, but it should be partially desolvated to be intruded into the pores.

The intruded volume increases at high $\mathrm{LiCl}$ concentration from $0.08 \mathrm{~mL} \mathrm{~g}^{-1}$ for $0 \mathrm{M}, 5 \mathrm{M}$ and $10 \mathrm{M} \mathrm{LiCl}$ aqueous solution to $0.11 \mathrm{~mL} \mathrm{~g}^{-1}$ for $20 \mathrm{M} \mathrm{LiCl}$ one. The explanation could be due to a more compact organization of the clusters of solvated ions from $\mathrm{LiCl}$ aqueous solution into the pores that allow a better filling of the porosity. ${ }^{30}$

Since both the pressure and the volume increase with LiCl concentration, the absorbed energy rise even more drastically $-6.6,9.5,14.0$ and $30.8 \mathrm{~J} \mathrm{~g}^{-1}$ for water, $5 \mathrm{M}, 10 \mathrm{M}$ and $20 \mathrm{LiCl}$ aqueous solutions, respectively. Thus, an absorbed energy increase of 4.7 times is observed, that it is considerably higher than in the case of other systems based on zeosils with 10 and $12 \mathrm{MR}$ openings $\left(\mathrm{MFI}^{35},{ }^{*} \mathrm{BEA}^{38}\right)$. It should be noticed that the absorbed energy by the "Si-ITH-20 M LiCl aqueous solution" system is among the highest ever observed. Only the systems based on MFl-type and LTA-type zeosils showed slightly higher values (31 and $32.6 \mathrm{~J} \mathrm{~g}^{-1}$, respectively).

SEM analysis. The Si-ITH samples were examined by scanning electron microscopy, before (Figure 3a) and after (Figure 3b) the intrusion-extrusion cycles in $20 \mathrm{M} \mathrm{LiCl}$ aqueous solution. 
Agglomerates of lamellar crystals of dimension of $2 \mu \mathrm{m} \times 5 \mu \mathrm{m}$ with the thickness of $\sim 50 \mathrm{~nm}$ are visible in Figure 3a. After intrusion-extrusion tests the crystals are considerably damaged.

XRD analysis. The XRD patterns of ITH-type zeosil before and after intrusion-extrusion experiments are reported in Figure 4.
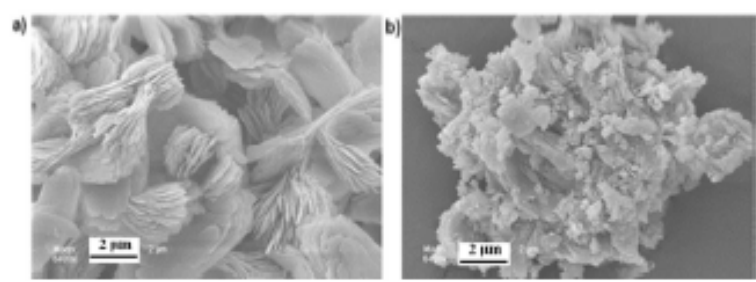

Figure 3. SEM micrograph of Si-ITH sample a) before and b) after three intrusion-extrusion cycles in $20 \mathrm{M} \mathrm{LiCl}$ aqueous solution.

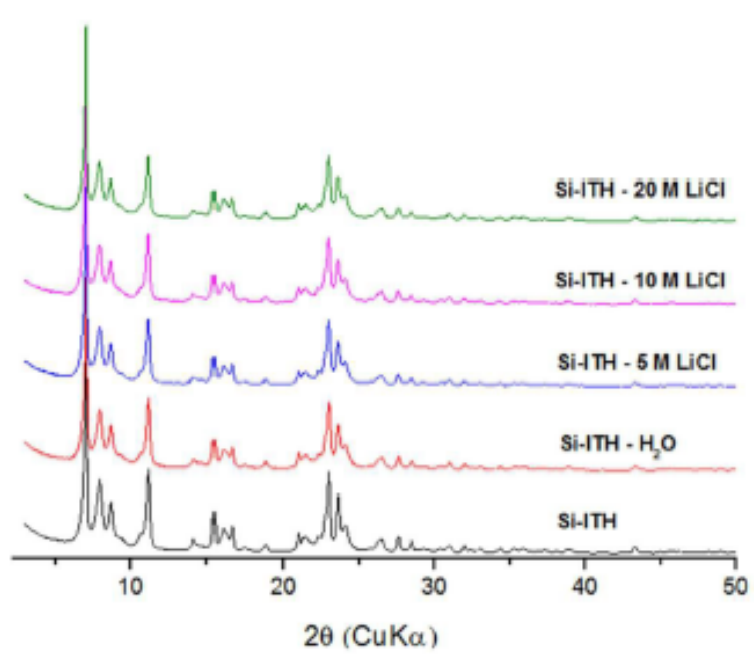

Figure 4. XRD patterns of Si-ITH samples before and after three intrusion-extrusion cycles in water, $5 \mathrm{M}, 10 \mathrm{M}$ and $20 \mathrm{M} \mathrm{LiCl}$ aqueous solution.

They are indexed in the orthorhombic symmetry (space group Amm2). From these XRD patterns, it seems that at the longrange order, the structure is not affected after intrusionextrusion experiments.

$\mathrm{N}_{2}$ adsorption-desorption isotherms. The $\mathrm{N}_{2}$ adsorptiondesorption isotherms of the nonintruded ITH-type zeosil sample is depicted in Figure 5. The isotherms of the intruded samples are shown in Figure \$1, because they are very close to the presented one. All the isotherms are mainly of type I characteristic of microporous solids. A high adsorbed volume at $p / p_{0}>0.9$ can be related with the high external surface of lamellar zeosil crystals. The corresponding BET surface $\left(\mathrm{S}_{\mathrm{BET}}\right)$ area and microporous volumes $\left(\mathrm{V}_{\text {micro }}\right)$ are reported in Table 2. The BET surface area and microporous volume is $471 \mathrm{~m}^{2} \mathrm{~g}^{-1}$ and $0.16 \mathrm{~cm}^{3} \mathrm{~g}^{-1}$, respectively, for the nonintruded $\mathrm{Si}-\mathrm{ITH}$ that is similar to the values reported in the literature. ${ }^{49}$ Almost the same values were obtained for the intruded samples. Thus, it can be supposed that the intrusion-extrusion cycles do not impact considerably the zeosil framework. The intruded volume of water and $\mathrm{LiCl}$ aqueous solutions is considerably lower $\left(0.08-0.11 \mathrm{~mL} \mathrm{~g}^{-1}\right)$, but it is in agreement with the work of Desbiens et

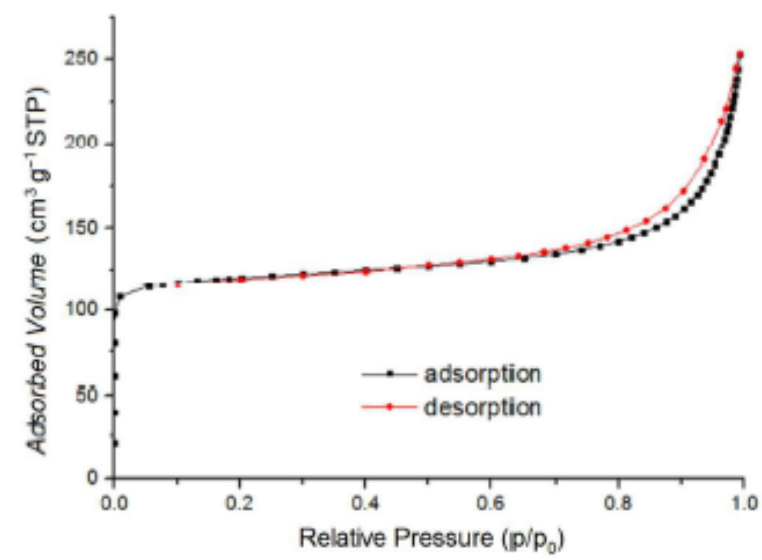

Figure 5. $\mathrm{N}_{2}$ adsorption-desorption isotherms at $77 \mathrm{~K}$ of the nonintruded Si-ITH sample.

Table 2. BET surface area and microporous volume values of Si-ITH samples before and after intrusion-extrusion experiments.

\begin{tabular}{lll}
\hline Sample & $\mathrm{S}_{\text {BET }}\left[\mathrm{m}^{2} \mathrm{~g}^{-1}\right]$ & $\mathrm{V}_{\text {micro }}\left[\mathrm{cm}^{3} \mathrm{~g}^{-1}\right]$ \\
\hline Si-ITH before intrusion & 471 & 0.16 \\
Si-ITH $-\mathrm{H}_{2} \mathrm{O}$ & 470 & 0.16 \\
Si-ITH $-5 \mathrm{M} \mathrm{LiCl}$ & 439 & 0.15 \\
Si-ITH $-10 \mathrm{M} \mathrm{LiCl}$ & 456 & 0.16 \\
Si-ITH $-20 \mathrm{M} \mathrm{LiCl}$ & 470 & 0.16 \\
\hline
\end{tabular}

al. ${ }^{50}$, where it was shown that the density of intruded water in the pores is considerably lower than in the bulk.

Thermogravimetric analysis. The results issued from the thermogravimetric (TG) analysis of the samples before and after intrusion-extrusion experiments are shown in Figure 6. The total weight loss is 1.6 wt \% for the nonintruded sample, but it increases for the intruded samples, up to $4.1 \mathrm{wt} \%$ for the ones intruded with 5 and $10 \mathrm{M} \mathrm{LiCl}$ aqueous solutions. Two main steps of weight loss are observed. The first one (with two different stages), situated between 30 and $300{ }^{\circ} \mathrm{C}$, is probably related with the desorption of the weakly and strongly adsorbed water molecules. The second one, in the 
temperature range of $300-700{ }^{\circ} \mathrm{C}$, can be ascribed to the dehydroxylation reactions of silanol groups.

The small total weight loss of the nonintruded sample (1.6 wt $\%)$ shows its hydrophobic character, indeed the dehydroxylation reactions (weight loss after $300^{\circ} \mathrm{C}$ close to 0.4 wt \%) leads to about $\sim 2 \mathrm{OH}$-groups per unit cell $\left(\mathrm{Si}_{56} \mathrm{O}_{112}\right)$. The increase of the weight loss after intrusion-extrusion experiments indicates that defect sites (OH-groups) are created under intrusion. The amount of the new silanol groups is almost the same for every intruded sample that is in agreement with the results of ${ }^{29} \mathrm{Si}$ MAS NMR analysis (see below). The weight loss after $300^{\circ} \mathrm{C}(0.8 \mathrm{wt} \%)$ corresponds to $\sim 4 \mathrm{OH}$-groups per

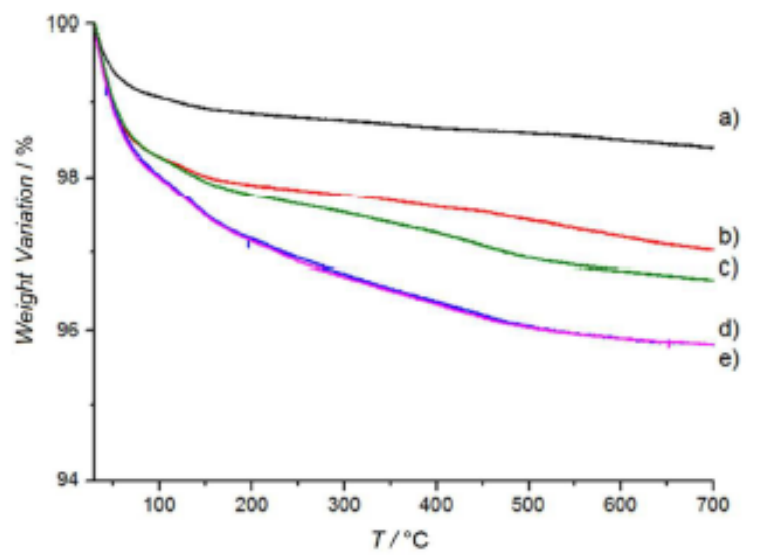

Figure 6. TG curves of the Si-ITH samples before (a) and after three intrusion-extrusion cycles in water (b), $20 \mathrm{M}$ (c), $5 \mathrm{M}$ (d) and $10 \mathrm{M} \mathrm{LiCl}(\mathrm{e})$ aqueous solution.

unit cell, that is also in agreement with NMR data. It is quite surprising that the intrusion of the most concentrated $20 \mathrm{M}$ $\mathrm{LiCl}$ solution leads to the formation of the same amount of defects in comparison with water and low concentrated $\mathrm{LiCl}$ aqueous solutions. It can be supposed that in the case of $20 \mathrm{M}$ $\mathrm{LiCl}$ aqueous solution, only a part of intruded solvated ions interact with the formed $\mathrm{OH}$-groups that can explain the partial reversibility of the system. This result is different from those the ones obtained for ${ }^{\text {} B E A}-{ }^{38}$ and LTA-type ${ }^{30}$ zeosils, where no defects formation was observed under the intrusion of highly concentrated $\mathrm{LiCl}$ solutions.

${ }^{29}$ Si MAS NMR spectroscopy. The ${ }^{29}$ Si MAS NMR spectra of the nonintruded and water-intruded Si-ITH samples are presented in Figure 7. The spectra of other intruded samples are shown in Figure S2, since they are superimposable to the one of water-intruded sample. Both spectra exhibit three resonances at $-110.6,-114.0$ and $-116.9 \mathrm{ppm}$ corresponding to $Q_{4}$ groups $\left(\mathrm{Si}-(\mathrm{OSi})_{4}\right)$. These peaks can be assigned to the nine nonequivalent crystallographic sites of the ITH framework. A small broad resonance is also detected at $-102.7 \mathrm{ppm}$. This peak can be attributed to $\mathrm{Q}_{3}$ groups ( $\mathrm{HO}-\mathrm{Si}-(\mathrm{OSi})_{3}$ or $-\mathrm{O}-\mathrm{Si}$ $\left.(\mathrm{OSi})_{3}\right)$ and corresponds to $3.1 \%$ and $6.8 \%$ of the total ${ }^{29} \mathrm{Si}$ signal before and after the intrusion-extrusion experiments, respectively. The increase of $Q_{3}$ groups content confirms the creation of defect sites and the obtained values are in good agreement with those determined from TG analysis (i.e., 2 and $4 \mathrm{OH}$ groups per unit cell for the nonintruded and intruded samples, respectively). With the exception of the increase of $Q_{3}$ groups, no significant change is observed between the spectra before and after intrusion-extrusion experiments.

${ }^{1} \mathrm{H}-{ }^{29} \mathrm{Si}$ CPMAS NMR spectroscopy. The ${ }^{1} \mathrm{H}-{ }^{29} \mathrm{Si}$ CPMAS NMR spectra recorded in the same conditions with short contact time (1 ms) of Si-ITH samples before and after intrusionextrusion experiments with water are shown in Figure 8. In agreement with the broad resonance observed in Figure 7, the presence of

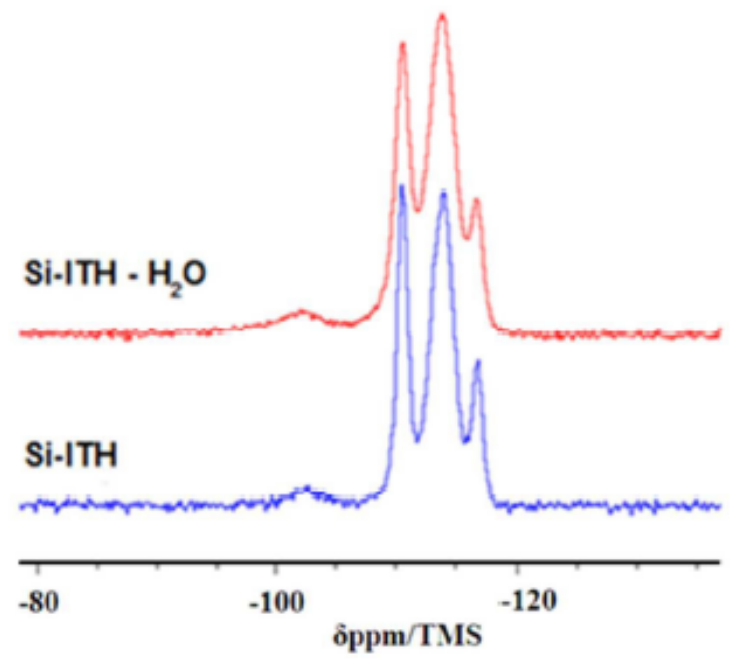

Figure 7. ${ }^{29} \mathrm{Si}-\mathrm{MAS}$ NMR spectra of the Si-ITH samples before and after three intrusion-extrusion cycles in water.

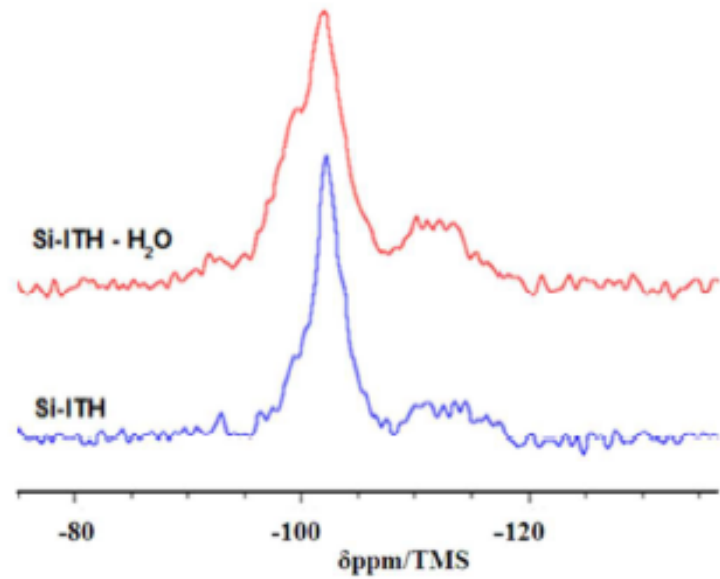

Figure 8. ${ }^{1} \mathrm{H}^{29} \mathrm{Si}$-CPMAS NMR spectra of the Si-ITH samples before and after three intrusion-extrusion cycles in water.

a resonance at $-102.4 \mathrm{ppm}$ corresponding to $\mathrm{Q}_{3}$ species is detected. Compared to the spectrum of the nonintruded 
sample, after the intrusion-extrusion experiments the $Q_{3}$ peak is broader due to a more intense component at $\sim-100 \mathrm{ppm}$ that was only slightly visible for the nonintruded sample. This result confirms the increase of the amount of the $Q_{3}$ species found by ${ }^{29} \mathrm{Si}$ MAS NMR analysis indicating the creation of silanol groups.

\section{Experimental}

Synthesis. The Si-ITH sample was synthesized in fluoride medium according to the procedure published by Corma et $a l^{33}$ using hexamethonium dihydroxide $\left(\mathrm{HM}(\mathrm{OH})_{2}\right)$ as structure-directing agent (SDA). The reactants used were: tetraethylorthosilicate (Evonik) as silica source, $\mathrm{HM}(\mathrm{Br})_{2}$ (Sigma-Aldrch) in its hydroxide form (obtained with Amberlyst A26 hydroxide form exchange resin) and $\mathrm{HF} \geq 40$ wt \% (sigmaAldrich). The starting gel (molar composition: $1 \mathrm{SiO}_{2}: 0.28 \mathrm{HM}$ $(\mathrm{OH})_{2}: 0.56 \mathrm{HF}: 7 \mathrm{H}_{2} \mathrm{O}$; seeds ( 2 wt \%/ $\left.\mathrm{SiO}_{2}\right)$ ) was introduced in a Teflon-lined stainless-steel autoclave and heated at $135^{\circ} \mathrm{C}$ during 24 days. After the synthesis, the product was filtered, washed with distilled water and ethanol, then dried in an oven at $70^{\circ} \mathrm{C}$ overnight. At the end the solid was calcined at $550^{\circ} \mathrm{C}$ under air for 6 hours to completely remove the organic template.

Characterization. The intrusion-extrusion of water and LiCl aqueous solutions in Si-ITH samples was performed at room temperature using a Micromeritics mercury porosimeter (Model Autopore IV), as described in a previous work. ${ }^{35}$

$X$-ray diffraction patterns were collected on a PANalytical MPD $X^{\prime}$ Pert Pro diffractometer operating with $\mathrm{Cu} \mathrm{K} \alpha$ radiation equipped with an X'Celerator real-time multiple strip detector (active length $=2.122^{\circ} 2 \theta$ ). The powder pattern was collected at $295 \mathrm{~K}$ in the range $3<2 \theta<50$, step $=0.017^{\circ} 2 \theta$, time $/$ step $=$ $220 \mathrm{~s}$, the total collecting time was about 90 minutes.

The size and the morphology of the crystals were determined by scanning electron microscopy (SEM) using a Philips XL 30 FEG microscope.

Nitrogen adsorption-desorption isotherms were performed at $77 \mathrm{~K}$ using a Micromeritics ASAP 2420 apparatus. Prior to the adsorption measurements, the samples were outgassed at 90 ${ }^{\circ} \mathrm{C}$ overnight to eliminate physisorbed water and to avoid the dehydroxylation process. The specific surface area $\left(\mathrm{S}_{\mathrm{BET}}\right)$ and microporous volume $\left(\mathrm{V}_{\text {micro }}\right)$ were calculated using the BET and t-plot methods, respectively.

Thermogravimetric (TG) analyses were carried out on a Mettler Toledo STARe apparatus, under air flow, with a heating rate of $5^{\circ} \mathrm{C} / \mathrm{min}$ from 30 to $700^{\circ} \mathrm{C}$.

${ }^{29} \mathrm{Si}$ MAS and ${ }^{1} \mathrm{H}^{29} \mathrm{Si}$ CPMAS NMR spectra were recorded at room temperature on a Bruker Advance II $300 \mathrm{MHz}$ spectrometer, with a double-channel $7 \mathrm{~mm}$ Bruker MAS probe. The recording conditions are given in Table 3.

Table 3. Recording conditions of the ${ }^{29} \mathrm{Si}$ MAS and ${ }^{1} \mathrm{H}-{ }^{29} \mathrm{Si}$ CPMAS NMR spectra.

\begin{tabular}{lll}
\hline & ${ }^{29} \mathrm{Si}$ MAS & ${ }^{1} \mathrm{H}^{29} \mathrm{Si}$ CPMAS \\
\hline Chemical Shift Standard & $\mathrm{TMS}^{\circ}$ & $\mathrm{TMS}^{\circ}$ \\
Frequency $(\mathrm{MHz})$ & 59.6 & 59.6 \\
Pulse width $(\mu \mathrm{s})$ & 2.17 & 5.00 \\
Flip angle & $\pi / 6$ & $\pi / 2$ \\
Contact time $(\mathrm{ms})$ & $/$ & 1 \\
Recycle time $(\mathrm{s})$ & 80 & ${ }^{(\bullet)} 1.5$ \\
Spinning rate $(\mathrm{kHz})$ & 4 & 4 \\
Scans number & 1700 & 10000 \\
\hline${ }^{a}=$ Tetramethylsilane; & ${ }^{\left({ }^{\circ}\right)}=$ the relaxation time $\mathrm{t}_{1}$ was optimized
\end{tabular}

\section{Conclusions}

The high pressure intrusion-extrusion of water and LiCl aqueous solutions has been studied for ITH-type zeosil, characterized by a 3D channel system with 10 and $9 \mathrm{MR}$ openings. A bumper behavior with an irreversible intrusion of water has been observed for the "ITH-type zeosil-water" system. The intrusion pressure of $82 \mathrm{MPa}$ is lower than for the most part of zeosils with channel pore systems and $10 \mathrm{MR}$ pore openings. The influence of $\mathrm{LiCl}$ concentration in aqueous solutions on behavior and energetic performances of "Si-ITHsolution" systems has been also studied. A rise of the intrusion pressure of 3.4 times has been observed: the pressure increases from $82 \mathrm{MPa}$ for water to $280 \mathrm{MPa}$ for $20 \mathrm{M} \mathrm{LiCl}$ aqueous solution. This increase is higher than that observed for MFI-type zeosil with very similar pore system. The absorbed energy rises from $6.6 \mathrm{~J} \mathrm{~g}^{-1}$ to $30.8 \mathrm{~J} \mathrm{~g}^{-1}$ for water and $20 \mathrm{M} \mathrm{LiCl}$ solution, respectively. The latter value is one of the highest ever observed for "zeosil-liquid" systems. A change of the system behavior with $\mathrm{LiCl}$ concentration has also been observed: from bumper behavior at low $\mathrm{LiCl}$ concentrations (water, $5 \mathrm{M}$ and $10 \mathrm{M}$ ) to a combination of bumper and shockabsorber behavior when $20 \mathrm{M} \mathrm{LiCl}$ aqueous solution is used. A similar trend was already observed for *BEA-type and LTA-type zeosils based systems, but in these cases a drastic decrease of the formation of defects was observed for the intrusion of highly concentrated solutions in comparison with water intrusion, whereas for ITH-type zeosil the increase of silanol defects is the same for all the liquids, as it was shown by TG and NMR analysis.

\section{References}

1 J. Čejka, H. Van Bekkum, A. Corma and F. Schüth in Introduction to Zeolite Science and Practice. Studies in Surface Science and Catalysis, 2007, 168, 1.

2 V. Eroshenko, R. C. Regis, M. Soulard and J. Patarin, J. Am. Chem. Soc., 2000, 123, 8129.

3 M. Soulard, J. Patarin, V. A. Eroshenko and R. Regis, Stud. Surf. Sci. Catal., 2004, 154B, 1830.

4 M. Trzpit, M. Soulard and J. Patarin, J. Phys. Chem. B, 2008, 112, 7257.

5 M. A. Saada, S. Rigolet, J.-L. Paillaud, N. Bats, M. Soulard and J. Patarin, J. Phys. Chem. C, 2010, 114, 11650. 
6 M.A. Saada, M. Soulard, B. Marler, H. Gies and J. Patarin, J. Phys. Chem. C, 2011, 115, 425.

7 L. Tzanis, M. Trzpit, M. Soulard and J. Patarin, Microporous Mesoporous Mater., 2011, 146, 119.

8 L. Tzanis, M. Trzpit, M. Soulard and J. Patarin, J. Phys. Chem. C, 2012, 116, 4802 .

9 L. Tzanis, M. Trzpit, M. Soulard and J. Patarin, J. Phys. Chem. C, 2012, 116, 20389

10 I. Khay, L. Tzanis, T. J. Daou, H. Nouali, A. Ryzhikov and J. Patarin, Phys. Chem. Chem. Phys., 2013, 15, 20320.

11 L. Tzanis, B. Marler, H. Gies and J. Patarin, J. Phys. Chem. C 2013, 117, 4098.

12 A. Ryzhikov, I. Khay, H. Nouali, T. J. Daou and J. Patarin, RSC Adv., 2014, 4, 37655.

13 O. V. levtushenko, V. A. Eroshenko, Y. G. Grosu, J.-M Nedelec and J.-P. Grolier, Phys. Chem. Chem. Phys., 2013, 15, 4451.

14 V. A. Eroshenko and Y. G. Grosu, J. Appl. Mech. Tech. Phys., 2013, 54, 798 .

15 V. Eroshenko, Int. Pat., WO96/18040, 1996.

16 T. Iwatsubo, C. V. Suciu, M. Ikenagao and K. Yaguchio, J. Sound Vib., 2007, 308, 579.

17 V. A. Eroshenko, J. Proc. Mech. Eng. Part J. Automob. Eng. 2007, 221, 285.

18 A. Laouir, L. Luo, D. Tondeur, T. Cachot and P. Le Goff, A/ChE J., 2003, 49, 764.

19 V.S. Egorov, A.G. Portyanoy, A.P. Sorokin, V.G. Maltsev, R.M Voznesensky and A.P. Ivchenko, Russ. Pat., 2138086, 1996.

20 V. A. Eroshenko and A. Popyk, IJoT, 2014, 17, 33.

21 V. A. Eroshenko, presented at MMT-2014 Conference, Ariel, Israel, July 2014, 2, 4-212.

22 A.Y. Fadeev, V. Eroshenko, J. Colloid Interface Sci., 1997, 187, 275

23 T. Martin, B. Lefevre, D. Brunel, A. Galarneau, F. Di Renzo, F. Fajula, P.F. Gobin, J.F. Quinson and G. Vigier, Chem. Commun., 2002, 1, 24.

24 Y. Grosu, O. levtushenko, V. Eroshenko, J.-M. Nedelec and J. P. Grolier, Colloids Surf. A, 2014, 441, 549.

25 G. Ortiz, H. Nouali, C. Marichal, G. Chaplais and J. Patarin, Phys. Chem. Chem. Phys., 2013, 15, 4888.

26 G. Ortiz, H. Nouali, C. Marichal, G. Chaplais, and J. Patarin, $J$. Phys. Chem. C, 2014, 118, 7321.

27 P. G. Yot, L. Vanduyfhuys, E. Alvarez, J. Rodriguez, J-P. Itié, P. Fabry, N. Guillou, T. Devic, I. Beurroies, P. L. Llewellyn, V. Van Speybroeck, C. Serre and G. Maurin, Chem. Sci., 2016, 7, 446.

28 Y. Grosu, M. Li, Y-L. Peng, D. Luo, D. Li, A. Faik, J-M. Nedelec and J.-P. Grolier, ChemPhysChem, 2016, 17, 3359.

29 Y. G. Bushuev, G. Sastre, J. V. De Julian-Ortiz and J. Galvez, J. Phys. Chem., 2012, C 116, 24916.

30 A. Ryzhikov, L. Ronchi, H. Nouali, T. J. Daou, J.-L. Paillaud and J. Patarin, J. Phys. Chem. C, 2015, 119, 28319.

31 M. Trzpit, M. Soulard and J. Patarin, Chem. Lett., 2007, 36, 980.

32 T. Boix, M. Puche, M. A. Camblor and A. Corma, US Pat., 6471941, 2002.

33 A. Corma, M. Puche, F. Rey, G. Sankar and S. J. Teat, Angew. Chem. Int. Ed., 2003, 42, 1156.

34 F. Cailliez, M. Trzpit, M. Soulard, I. Demachy, A. Boutin, J. Patarin and A. H. Fuchs, Phys. Chem. Chem. Phys., 2008, 10, 4817.

35 I. Khay, T. J. Daou, H. Nouali, A. Ryzhikov, S. Rigolet and J. Patarin, J. Phys. Chem. C, 2014, 118, 3935.

36 M. Soulard and J. Patarin, French Pat., FR2976030, 2011.

37 L. Tzanis, H. Nouali, T. J. Daou, M. Soulard and J. Patarin, Mater. Lett., 2014, 115, 229.

38 A. Ryzhikov, I. Khay, H. Nouali, T. J. Daou and J. Patarin, Phys. Chem. Chem. Phys., 2014, 16, 17893.
39 C. E. A. Kirschhock, M. De Prins, E. Verheijen, A. Ryzhikov, T. J. Daou, H. Nouali, F. Taulelle, J. A. Martens and J. Patarin, Phys. Chem. Chem. Phys., 2016, 18, 18795

40 A. Han and Y. Qiao, J. Mater. Res., 2007, 22, 644.

41 A. Han, W. Lu, T. Kim, V. K. Punyamurtula and Y. Qjao, Smart Mater. Struct., 2009, 18, 024005.

42 L. Liu, X. Chen, W. Lu, A. Han and Y. Qjao, Phys. Rev. Lett., 2009, 102, 184501

43 E. W. Washburn, Proc. Natl. Acad. Sci. U. S. A., 1921, 7, 115.

44 [44] W. Peiming, A. Anderko and R. D. Young, Ind. Eng. Chem. Res., 2011, 50, 4086.

45 M. Michelin-Jamois, C. Picard, E. Charlaix and G. Vigier, 2014 ArXiv: Physicschem-Ph/14045318v1.

46 M. Michelin-Jamois, C. Picard, G. Vigier and E. Charlaix, Phys. Rev. Lett., 2015, 115, 036101

47 A. Han, V. K. Punyamurtula and Y. Qiao, Appl. Phys. Lett. 2008, 92, 153117.

48 R. Arletti, L. Ronchi, S. Quartieri, G. Vezzalini, A. Ryzhikov, H. Nouali, T.J. Daou and J. Patarin, Microporous Mesoporous Mater., 2016, 235, 253.

49 G. Xu, X. Zhu, X. Li, S. Xie, S. Liu and L. Xu, Microporous Mesoporous Mater. 2010, 129, 278.

50 N. Desbiens, I. Demachy, A. H. Fuchs, H. Kirsch-Rodeschini, M. Soulard and J. Patarin, Angew. Chem. Int. Ed., 2005, 44, 5310. 